\title{
Herbivores do not discriminate between leaves of female and hermaphrodite individuals of gynodioecious Daphne laureola (Thymelaeaceae)
}

\author{
Conchita Alonso
}

\begin{abstract}
Alonso, C. 2003. Herbivores do not discriminate between leaves of female and hermaphrodite individuals of gynodioecious Daphne laureola (Thymelaeaceae). Oikos 101: 505-510.

The outcome of plant-animal interactions in dioecious plant species frequently depends on the gender of the plant individuals. It has even been proposed that these interactions could mediate the evolution of plant reproductive systems from hermaphroditism to dioecy. Gynodioecy is the most frequent intermediate stage in this evolutionary process, however, little is known about the relevance of gender dimorphism in plant-animal relationships others than pollination for gynodioecious species. In this study herbivores (Noctuid larvae) were used as subjective referees to detect differences between leaves of female and hermaphrodite Daphne laureola individuals. Larvae collected in the field were allowed to choose between leaves of female and hermaphrodite individuals at both flowering and fruiting period. There was no preference for either of the genders suggesting that the absence of male reproductive function in $D$. laureola shrubs does not cause dissimilarities in leaf characteristics that can affect herbivores.
\end{abstract}

Gynodioecy results when a male-sterile mutant ("female" hereafter) invades and becomes established in a co-sexual plant population (Webb 1999). For the polymorphism to be maintained in the population, specialization in female function should increase individual fitness, and the female advantages can arise from resource compensation, inbreeding avoidance or less detrimental interactions with herbivores, pathogens and competitors. In particular, herbivores have been suggested to contribute to the divergence of female and male reproductive functions into separate plant individuals because defoliation often affects more negatively the male function of hermaphrodites (Mutikainen and Delph 1996). Additionally, herbivores usually distinguish and prefer males over females of dioecious plant species (Agren et al. 1999) suggesting that differences in reproductive allocation modify other plant features that in turn affect their quality as food for herbivores
(Boecklen et al. 1990, Jing and Coley 1990). There is also some evidence for sex-biased flower and seed predation favouring the maintenance of females in gynodioecious populations (Uno 1982, Marshall and Ganders 2001, Collin et al. 2002; reviewed by Ashman 2002).

Despite gynodioecy being supposed the most frequent intermediate stage in the evolution from hermaphroditism to dioecy (Webb 1999) and that herbivores might be mediating this process (Mutikainen and Delph 1996), plant-herbivore interactions of gynodioecious species remain almost completely unexplored except for the seed and flower consumers mentioned above (Ashman 2002). To my knowledge, only Delph $(1990,1993)$ has demonstrated that the consequences of experimental defoliation in terms of growth and seed production can differ among hermaphrodites and females. However, we do not know if herbivore defoliators can distinguish between individuals appar- 
ently differing only in the presence/absence of male function, if herbivores' performance changes depending on the plant gender they are feeding on, or if plant gender determines natural defoliation in gynodioecious species. In principle, if male sex function is costly as Eckhart and Seger (1999) have suggested, we would expect that, as in dioecious species, differences between hermaphrodites and females in their allocation to sexual reproduction could induce further dissimilarities in terms of growth rates, phenology, floral display, concentrations of nutrients and secondary compounds, size or foliage abundance, that in turn would affect attraction to herbivores and/or consumption.

The main goal of this study was to test whether leaves of hermaphrodite and female Daphne laureola L. (Thymelaeaceae) shrubs were actually discriminated by their main herbivores, the larvae of noctuid moths (Lepidoptera, Noctuidae). Responses of herbivores were analyzed by studying larval selection in choice experiments, and subsequently evaluating the consequences of the selection in terms of larval performance. Since experience and learning may modify food preference of arthropods (Egas and Sabelis 2001), half of the study larvae were collected from $D$. laureola females and the other half from hermaphrodites to test for the effect of plant gender provenance on larval food selection. The same individual larvae were allowed to choose twice to evaluate the consistency of their selection behavior.

The experiment was conducted twice at flowering and fruiting, because, as Agren et al. (1999) have remarked also for dioecious species, gender differences may vary along the season as long as the allocation to reproductive function varies (Delph 1990). In particular, hermaphrodite and female $D$. laureola plants produce similar number of flowers (Alonso and Herrera 2001), however, female flowers are smaller and pollenless and therefore they may be less costly. Thus, the a priori prediction was that these differences in allocation to reproduction between the genders at flowering peak (Ç 90\% flowers opened) would result in further differences of leaf characteristics that could in turn affect herbivores. However, at fruit development period herbivore discrimination between genders was not expected because female and hermaphrodite $D$. laureola individuals do not differ in fruit production or fruit size (Alonso and Herrera 2001).

\section{Methods}

\section{Study species}

Daphne laureola L. is an evergreen gynodioecious shrub that, in the Mediterranean region, occupies preferentially the undergrowth of mixed mountain forests (Nieto Feliner 1997). Leaves are found only at the distal portion of each branch, forming a single, well-defined rosette ("leaf whorl" hereafter). In the study site at Natural Park of Sierras de Cazorla-Segura-Las Villas (Jaén province, southeastern Spain), flowering begins in early February and leaves start growing a few weeks later. Expansion of new leaves is rather slow and takes place from mid-March to mid-May. Fruits begin to develop once leaf expansion has started and they ripen in early/mid-June. Plants shed their oldest leaves in early summer, when the expansion of new leaves has finished. Individual plants of both genders do not differ significantly in size, leaf production, leaf size, leaf growth, nutrient composition of final-sized leaves, or production of flowers and fruits (Alonso and Herrera 2001). Female flowers are smaller $(12.94 \pm 2.0 \mathrm{mg})$ than the hermaphrodite ones (24.58 $\pm 4.72 \mathrm{mg})$.

In the study area, larvae of noctuid moths (Lepidoptera, Noctuidae) were the only herbivores recorded feeding on the foliage of $D$. laureola plants from late winter to early summer during three consecutive field seasons (1994-1996; C. Alonso, unpubl.). The species observed were Trigonophora flammea Esper., Noctua janthe Bkh., N. fimbriata Schreber, and Pseudenargia ulicis Staud. They all have nocturnal habits, feeding on the $D$. laureola leaf whorls during the night and spending daytime on the ground, hidden in the litter (Alonso and Herrera 1996). Like most species in the Noctuidae (Niemelä et al. 1981, Jallow and Zalucki 1995), these are generalist herbivores that also feed on a variety of other plants in the study area (e.g. Narcissus longispathus, Paeonia broteroi, Helleborus foetidus, Primula uulgaris).

\section{Feeding experiments}

Discrimination of caterpillars between leaves of female and hermaphrodite $D$. laureola individuals was determined by choice experiments during the 2001 feeding season. That year Noctua larvae were the most abundant and thus, individuals of the other species were not used in the experiments. Trials were conducted at night, resembling the normal activity period of the larvae, at two different dates: on March 28-29 when D. laureola plants have Ç $90 \%$ of flowers opened, and on May 1-2 when all fruits were still green. Caterpillars used for the trials were collected at sunset from female and hermaphrodite $D$. laureola plants at the study area and placed individually into $15-\mathrm{cm}$ labeled petri dishes. The number and identity of plants visited varied between dates according to caterpillars availability. In every petri dish I placed two current season $D$. laureola leaves, one of each plant gender, collected simultaneously from haphazardly selected individuals excluding those where larvae were collected from. Fresh mass of the leaves and larvae were recorded at the beginning of each trial. Caterpillars were singly placed in the 
center of the petri dish and equidistant from the two leaves that were alternatively placed right and left from the observer viewpoint. Room temperature during trials was $12-13^{\circ} \mathrm{C}$.

On each occasion, larvae $(\mathrm{N}=30$ in March and $\mathrm{N}=28$ in May) were tested for two consecutive nights to check for consistency of their behaviour. Larvae were allowed to feed for the whole night $(=9 \mathrm{~h})$, then they were re-weighed and left in the petri dish without food until the next night when new fresh leaves were offered to them. At the end of each experimental night leaf surface consumed was estimated by using a reticulated paper and leaves were re-weighed. Five control petri dishes, where no caterpillar was included, were added to the experiment and handled in the same way to estimate water loss rate of leaves during the experimental period. For each date, final leaf weight was regressed without intercept on initial leaf weight. The regression coefficients ( \pm s.e.) obtained for the first and second night respectively were $0.9048( \pm 0.002)$ and 0.9083 ( \pm 0.003$)$ at flowering, and 0.9293 ( \pm 0.004 ) and $0.9192( \pm 0.005)$ at fruiting. These coefficients were used to compute the expected post-experiment mass of leaves in the absence of consumption. The difference between real and expected mass was used as a quantitative estimate of consumed biomass. The relationship between consumed leaf area and consumed biomass was linear, statistically significant $(P<0.0001)$ and tight $\left(\mathrm{R}^{2}>0.90\right)$ in all cases. Thus, only consumed biomass was used in further analyses.

\section{Data analysis}

All analyses were performed using the SAS statistical package (SAS Institute 1996). Figures are indicated as mean $( \pm \mathrm{SD})$ unless otherwise stated.

Proportion of female leaf consumed within each petri dish was used as an estimate of plant gender selection by individual larvae. This variable was not normally distributed and Generalized Linear Models (Proc GENMOD), with binomial distribution, Pearson scale and probit link function, were used to test for the effect of different factors on this variable. The Spearman correlation coefficient between the proportion of female leaf consumed in two consecutive nights was used to estimate consistency of selection behavior of individual larva at each study date.

The consequences for larvae of their feeding behaviour were explored by using path analysis (Proc CALIS). The initial theoretical model (Fig. 1) considered that, first, if $D$. laureola genders differed in quality, and provided that mobility of these larvae is quite restricted (C. Alonso, pers. obs.), the gender of the plant on which larvae had been collected from could affect either the size of the larvae at collection date, or their discrimination between genders (i.e. \% female leaf consumed). Plant gender was treated as a dummy variable by assigning 1 to females and 0 to hermaphrodites. Second, variation in the percentage of female leaf consumed could affect larval growth either directly, via efficiency, or indirectly through consumption. Finally, larval body size directly determined consumption, and consumption in turn determined growth. Model goodness-of-fit was assessed by $z^{2}$ test and Normed Fit Index (NFI) (Hatcher 1994). Significance of path coefficients was estimated by using boostrap analysis $(\mathrm{N}=$ 5000 repetitions) because the dummy variable and the $\%$ female leaf consumed did not satisfy the condition of normality and sample sizes were rather small for using a parametric test. For the second night's experiments, other models that included previous night food selection and total consumption were tested. However, the path coefficients were far from being statistically significantly different from zero and the models did not improve their goodness-of-fit by including them. Therefore, results have been omitted.
Fig. 1. Path diagram showing the expected causal relationships between provenance, behaviour and performance of the larvae. Single headed arrows indicate direct relations and have associated a path coefficient (p1,.., p6). Each of the residual variables $\left(\mathrm{U}_{1}, \ldots, \mathrm{U}_{5}\right)$ represents the unmeasured factors that affect a given dependent variable and that are unexplained by the path diagram.

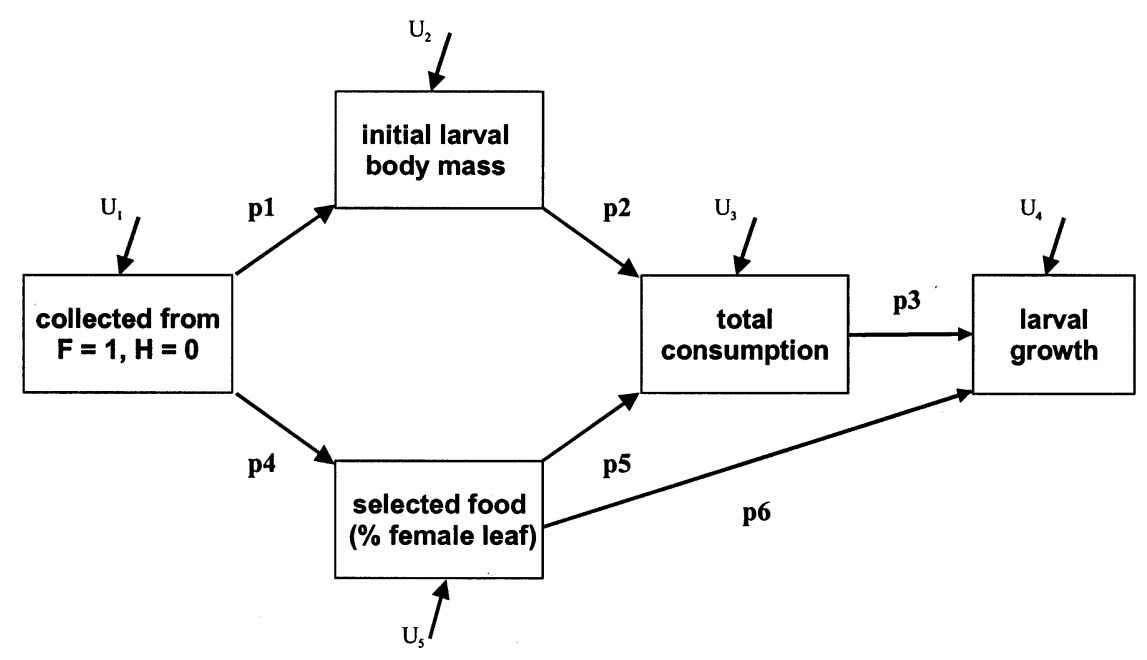




\section{Results}

At flowering time, average larval body mass at collection was 141.1 ( \pm 55.2$) \mathrm{mg}$ fresh mass and the total leaf consumption was $23.9 \mathrm{mg}( \pm 11.1$ ) and $32.6 \mathrm{mg}$ ( \pm 13.2), at first and second night respectively. In the first night, $20 \%$ of larvae fed only on hermaphrodite leaf, $36.67 \%$ fed on only female leaf and $43.33 \%$ fed on both leaves. In the second night, mixed consumption was also the most frequent case (46.67\%), followed by consumption of only female leaf (30\%) and only hermaphrodite leaf (23.33\%). The proportion of female leaf consumed was not related to the plant gender from which larvae had been collected (Wald's $z^{2}=0.75, \mathrm{df}=$ $1, P=0.39$; Wald's $z^{2}=0.63$, $\mathrm{df}=1, P=0.43$ for the first and second study nights respectively). More interestingly, the correlation between food selection at first and second night was not statistically significant $\left(r_{S}=\right.$ $-0.03, \mathrm{~N}=29, P=0.88$ ).

At fruiting time, average larval body mass at collection was 345.7 ( \pm 162.0 ) $\mathrm{mg}$ fresh mass and the total leaf consumption was $43.4 \mathrm{mg}$ (士27.6) and $77.2 \mathrm{mg}$ ( \pm 46.9 ) at first and second night, respectively. During the first study night, $42.86 \%$ of larvae fed on only hermaphrodite leaves, whereas $28.57 \%$ fed on female leaves only and $28.57 \%$ fed on both types of leaves. During the second study night, mixed consumption was the most frequent case (65.38\%). $19.23 \%$ of larvae fed on only hermaphrodite leaves and $15.38 \%$ fed on female leaves only. Correlation between leaf gender selection at first and second study nights was not statistically significant $\left(r_{S}=-0.011, \mathrm{~N}=26, P=0.95\right.$, excluding two larvae that did not eat at all during the second night). The proportion of female leaf consumed was not related to the gender of the plant from which the larvae had been collected (Wald's $z^{2}=1.64$, $\mathrm{df}=1, P=0.20$; Wald's $z^{2}=0.45$, df $=1, P=0.50$ for the first and second study nights respectively).

The consequences for larvae of their food mixture were explored by using path analysis. Goodness-of-fit analyses indicated that the proposed model (Fig. 1) provided a good fit to the data obtained during the first study night at both flowering and fruiting time, but not so good for the second study night of each experiment (Table 1). Initial size of larvae collected at flowering time was significantly related to the gender of the plant they had been collected from (p1) indicating that larvae found on flowering hermaphrodites were heavier (159.8 $\pm 67.2 \mathrm{mg}$ vs $122.3 \pm 32.3 \mathrm{mg} ; F_{1,28}=3.80, P=$ 0.06 ), but this relationship disappeared in the second study night. As expected from the results showed above, no significant direct effect of larval gender provenance on leaf gender selection was observed in any experiment (Table 1, p4) supporting the idea that previous experience did not modify larval behavior. Finally, gender selection did not significantly affect either consumption (p5) or growth (p6), suggesting that the genders had similar quality for these herbivores. Only the well known positive causal relationship between size and consumption (Table 1,p2), and between consumption and growth (p3) were consistently significant in all experiments. On average relative consumption decreased from flowering $(0.17 \pm 0.06$ and $0.25 \pm 0.11 \mathrm{mg}$ leaf $/ \mathrm{mg}$ larva, at first and second night respectively) to fruiting time $(0.12 \pm 0.06$ and $0.23 \pm$ $0.10 \mathrm{mg}$ leaf $/ \mathrm{mg}$ larva). The same was also true for the relative growth $(0.08 \pm 0.05$ and $0.13 \pm 0.07$ at flowering; $0.05 \pm 0.04$ and $0.09 \pm 0.08$ at fruiting time).

\section{Discussion}

The importance of male reproductive function of plants was traditionally neglected until some studies proved that although both female and male reproductive functions are often positively related (Campbell 2000), they do not always respond equally to selection pressures as, for instance, herbivory (Mutikainen and Delph 1996, Agrawal et al. 1999). The exceptions where female and male function are not positively related are particularly interesting since they may elucidate the evolutionary pathways of plant reproductive systems (Ashman 1999).

Females of gynodioecious species provide a natural treatment to test for the resource allocation, and fitness costs and benefits associated to the male function.

Table 1. Model goodness-of-fit and path coefficients (see Fig. 1 for details) estimated at both flowering and fruiting time. Non-significant $\mathrm{ç}^{2}$ tests and Normed Fit Index (NFI) $>0.9$ indicate good fit of data to model. Coefficients marked in bold were found to be statistically significantly different from zero at $95 \%$ confidence by using boostrap ( $\mathrm{N}=5000$ repetitions).

\begin{tabular}{|c|c|c|c|c|}
\hline Model & Flowering 1st night & Flowering 2nd night & Fruiting 1st night & Fruiting 2nd night \\
\hline Goodness-of-fit & $\begin{array}{l}\mathrm{z}_{4}^{2}=2.0, P=0.73 \\
\mathrm{NFI}=0.97\end{array}$ & $\begin{array}{l}z_{4}^{2}=7.7, P=0.10 \\
\text { NFI }=0.86\end{array}$ & $\begin{array}{l}\mathrm{z}_{4}^{2}=3.4, P=0.49 \\
\mathrm{NFI}=0.94\end{array}$ & $\begin{array}{l}z_{4}^{2}=20.4, P<0.05 \\
N F I=0.68\end{array}$ \\
\hline \multicolumn{5}{|l|}{ Parameters } \\
\hline p1 & -0.37 & -0.28 & -0.11 & -0.11 \\
\hline $\mathrm{p} 2$ & 0.72 & 0.41 & 0.81 & 0.73 \\
\hline p3 & 0.91 & 0.88 & 0.78 & 0.78 \\
\hline p4 & -0.25 & 0.08 & 0.12 & -0.07 \\
\hline p5 & -0.06 & -0.0002 & 0.05 & 0.19 \\
\hline p6 & -0.007 & 0.01 & 0.02 & -0.08 \\
\hline
\end{tabular}


Results about costs of male reproductive function in gynodioecious species are controversial (Eckhart and Seger 1999) and, as previously stated, the relationships with herbivores remain practically unexplored. The present experiment was planned to test whether differences in resource allocation to male function between female and hermaphrodite $D$. laureola individuals modify some leaf traits that could indicate a cost of the male function. In a previous study (Alonso and Herrera 2001) reproductive parameters, and nutrient composition and physical characteristics of mature leaves of $D$. laureola genders were found to be similar. Here, herbivores were used as subjective referees to detect potential differences between leaf gender in other traits (e.g. secondary chemistry) that have not been analyzed, and that could be related to plant resistance by modifying attraction to herbivores or herbivores performance.

Insect feeding decisions may be modified by previous experience, with insects often preferring the diet they have previously eaten (Karowe 1989, Bernays and Weiss 1996) although this has not been always observed (Egas and Sabelis 2001). In this study, Noctua larvae did not apparently prefer any of the two D. laureola genders, and individual selection was not affected by the gender of the plant from which each larva had been collected. Relative abundance of trials where larvae fed on both offered leaves and inconsistency among individual selection behavior in consecutive nights support the idea that Noctua larvae do not discriminate between leaves of $D$. laureola genders.

Short-term larval growth experiments have been found to be efficient for detecting intraspecific differences in leaf quality (Kause et al. 1999). In this study, path analysis showed that food selection of the larvae was not directly related to either consumption or growth suggesting that variation in the proportion of female and hermaphrodite leaves consumed did not modify short-term larval performance. Only the well established positive relationships between larval size and consumption (p2) and between consumption and growth (p3) were consistently positive. Mean relative consumption and growth observed indicated that the quality of the leaves decreased gradually during the season (Alonso and Herrera 2000). It struck me that path analyses obtained for the first night, when larvae had been directly collected in the field, were more comprehensible than those for the second study night when larval condition were supposed to be more homogeneous. In particular, the correspondence between larval size and consumption the second study night of flowering time decreased due to the effect of previous night consumption and indicates that variation in the speed of digestion can alter results obtained for small larvae.

It is remarkable that larvae collected from hermaphrodite plants at the flowering peak were significantly heavier than larvae collected from female plants.
According to sex allocation theory, at flowering peak hermaphrodites allocate less resources than females to other functions such as defense, and therefore larvae feeding on hermaphrodites could benefit from a more palatable food. The difference in size could also arise because Noctua larvae also eat $D$. laureola flowers (C. Alonso, pers. obs.) and hermaphrodite flowers are probably more nutritious than the smaller and pollenless female flowers (Roulston and Cane 2000). Both reasoning could also explain that the same relationship was not found at fruiting time.

To sum up, Noctua larvae seemed to be unable to behaviorally discriminate between the leaves of $D$. laureola genders, and thus as defoliators they are not likely to be directly contributing to the evolution of the gynodioecious reproductive system of this species. The wide host-range of the herbivore is probably beneath its observed non-selective behaviour (Singer 2001) and might partially explain why, in contrast to the results reported here, other more selective herbivores feeding on seeds and flowers can usually discriminate between plant genders (Ashman 2002).

Acknowledgements - I thank Rocío Ruíz for her assistance during field work; Carlos M. Herrera and Estación Biológica de Doñ ana for the support and facilities provided to conduct the study; Consejería de Medio Ambiente for authorizing me to work in Cazorla; and José R. Obeso, Seppo Neuvonen and Pia Mutikainen for their constructive comments on the manuscript. The study was funded by a Marie Curie Fellowship (HMPF-CT-2000-01095).

\section{References}

Agrawal, A. A., Strauss, S. Y. and Stout, M. J. 1999. Costs of induced responses and tolerance to herbivory in male and female fitness components of wild radish. - Evolution 53: 1093-1104.

Agren, J., Danell, K., Elmqvist, T. et al. 1999. Sexual dimorphism and biotic interactions. - In: Geber, M. A., Dawson, T. E. and Delph, L. F. (eds), Gender and sexual dimorphism in flowering plants. Springer, pp. 217-246.

Alonso, C. and Herrera, C. M. 1996. Variation in herbivory within and among plants of Daphne laureola (Thymelaeaceae): correlation with plant size and architecture. - J. Ecol. 84: 495-502.

Alonso, C. and Herrera, C. M. 2000. Seasonal variation in leaf characteristics and food selection by larval noctuids on an evergreen Mediterranean shrub. - Acta Oecol. 21: 257265.

Alonso, C. and Herrera, C. M. 2001. Neither vegetative nor reproductive advantages account for high frequency of male-steriles in southern Spanish gynodioecious Daphne laureola (Thymelaeaceae). - Am. J. Bot. 88: 1016-1024.

Ashman, T.-L. 1999. Determinants of sex allocation in a gynodioecious wild strawberry: implications for the evolution of dioecy and sexual dimorphism. - J. Evol. Biol. 12: 648-661.

Ashman, T.-L. 2002. The role of herbivores in the evolution of separate sexes from hermaphroditism. - Ecology 83: $1175-1184$

Bernays, E. A. and Weiss, M. R. 1996. Induced food preferences in caterpillars: the need to identify mechanisms. Entomol. Exp. Appl. 78: 1-8. 
Boecklen, W. J., Price, P. W. and Mopper, S. 1990. Sex and drugs and herbivores: sex-biased herbivory in arroyo willow (Salix lasiolepis). - Ecology 71: 581-588.

Campbell, D. R. 2000. Experimental tests of sex-allocation theory in plants. - TREE 15: 227-232.

Collin, C. L., Pennings, P. S., Rueffler, C. et al. 2002. Natural enemies and sex: how seed predators and pathogens contribute to sex-differential reproductive success in a gynodioecious plant. - Oecologia 131: 94-102.

Delph, L. F. 1990. Sex-differential resource allocation patterns in the subdioecious shrub Hebe subalpina. - Ecology 71: $1342-1351$.

Delph, L. F. 1993. Factors affecting intraplant variation in flowering and fruiting in the gynodioecious species Hebe subalpina. - J. Ecol. 81: 287-296.

Eckhart, V. M. and Seger, J. 1999. Phenological and developmental costs of male function in hermaphroditic plants. In: Vuorisalo, T. O. and Mutikainen, P. K. (eds), Life history evolution in plants. Kluwer, pp. 195-213.

Egas, M. and Sabelis, M. W. 2001. Adaptive learning of host preference in a herbivorous arthropod. - Ecol. Lett. 4: 190-195.

Hatcher, L. 1994. A step-by-step approach to using the SAS ${ }^{\circledR}$ System for factor analysis and structural equation modeling. - SAS Institute Inc., Cary NC.

Jallow, M. F. A. and Zalucki, M. P. 1995. A technique for measuring intraspecific variation in oviposition preference in Helicouerpa armigera (Hübner) (Lepidoptera: Noctuidae). - J. Aust. Ent. Soc. 34: 281-288.

Jing, S. W. and Coley, P. D. 1990. Dioecy and herbivory: the effect of growth rate on plant defense in Acer negundo. Oikos 58: 369-377.

Kause, A., Haukioja, E. and Hanhimäki, S. 1999. Phenotypic plasticity in foraging behavior of sawfly larvae. - Ecology 80: $1230-1241$.
Karowe, D. N. 1989. Facultative monophagy as a consequence of prior feeding experience: behavioral and physiological specialization in Colias philodice larvae. Oecologia 78: 106-111.

Marshall, M. and Ganders, F. R. 2001. Sex-biased seed predation and the maintenance of females in a gynodioecious plant. - Am. J. Bot. 88: 1437-1443.

Mutikainen, P. and Delph, L. F. 1996. Effects of herbivory on male reproductive success in plants. - Oikos 75: 353358.

Niemelä, P., Hanhimäki, S. and Mannila, R. 1981. The relationship of adult size in noctuid moths (Lepidoptera, Noctuidae) to breadth form of host plants. - Ann. Entomol. Fenn. 47: 17-20.

Nieto Feliner, G. 1997. Thymelaeaceae. - In: Castroviejo, S., Aedo, C., Benedí, C. et al. (eds), Flora Iberica, vol. VIII, Haloragaceae-Euphorbiaceae. Real Jardín Botánico, CSIC, Madrid, Spain, pp. 32-69.

Roulston, T. H. and Cane, J. H. 2000. Pollen nutritional content and digestibility for animals. - Plant Syst. Evol. 222: $187-209$.

SAS Institute 1996. SAS/STAT software: changes and enhancements through Release 6.11. - SAS Institute, Cary, North Carolina.

Singer, M. S. 2001. Determinants of polyphagy by a woolly bear caterpillar: a test of the physiological efficiency hypothesis. - Oikos 93: 194-204.

Uno, G. E. 1982. Comparative reproductive biology of hermaphroditic and male-sterile Iris douglasiana Herb. (Iridaceae). - Am. J. Bot. 69: 818-823.

Webb, C. J. 1999. Empirical studies: evolution and maintenance of dimorphic breeding systems. - In: Geber, M. A., Dawson, T. E. and Delph, L. F. (eds), Gender and sexual dimorphism in flowering plants. Springer, pp. 6195. 